\title{
Forthcoming Meetings and Short Courses
}

This section carries meetings of interest to synchrotron radiation scientists, including meetings of scientific societies, congresses, summer schools etc. Details of meetings for inclusion here in print and on the World Wide Web at URL http://www.iucr.org/cww-top/mtg.date.html, subject to the approval of the Editorial Board, should be sent to the Editorial Office, 5 Abbey Square, Chester $\mathrm{CH} 12 \mathrm{HU}$, UK. E-mail: med@iucr.ac.uk.

1998

22 February-3 April 1998: Grenoble, France. Two HERCULES Courses: Neutron and Synchrotron Radiation for (i) Physics and Chemistry of Condensed Matter (ii) Biomolecular Structure and Dynamics. For further information contact Secretariat Hercules, CNRS, Maison des Magistères, BP 156, F-38042 Grenoble CEDEX 9, France.

6-14 May 1998: Luso, Portugal. ESRS Summer School: Applications of Synchrotron Radiation in Materials Science and Physics. For further information contact Mrs Sandra Beaufoy. Fax: +44 1203 692016; E-mail: esrs@spec.warwick.ac.uk; http://fy.chalmers.se/esrs/luso.html.

14-20 June 1998: Jaszowiec, Poland. International School and Symposium on Synchrotron Radiation in Natural Science. For further information contact Dr Sc. K. Lawniczak-Jablonska, Institute of Physics, PAS, Al. Lotnikow 32/46, 02668 Warsaw, Poland. Fax: +48-22-430926; Email: synchro@ifpan.edu.pl.

1-5 August 1998: Ascona, Switzerland. 1st SLS Workshop on Synchrotron Radiation: Applications of Highly Brilliant and Coherent Synchrotron Radiation. For further information contact http://www1.psi.ch/www_sls_hn/workshops/ sls_ascona_aug98.htmlx.

3-7 August 1998: San Francisco, CA, USA. 12th International Conference on Vacuum Ultraviolet Radiation Physics. For further information contact vuv12@lbl.gov; http://www-als.lbl.gov/als/vuv12/index.html.

4-8 August 1998: Argonne, IL, USA. Biophysics and Synchrotron Radiat- ion: BSR98. For further information contact Keith Moffat. E-mail: moffat (8) cars1.uchicago.edu; http://www.aps.anl.gov /conferences/bsr/bsr98.html.

10-14 August 1998: Chicago, IL, USA $X$-ray Absorption Fine Structure (XAFS X). For further information contact Professor T. I. Morrison, c/o Toni Mitchell, XAFS X Secretariat, Center for Synchrotron Radiation Research and Instrumentation, Illinois Institute of Technology, 3101 South Dearborn Street, Chicago, Illinois 60616, USA. Tel: +1 312567 3580; Fax: +1 312567 3494; E-mail: XAFSX@ixs.iit.edu; http://ixs.iit.edu/ xafs.

23-28 August 1998: Chicago, IL, USA XIX International Linear Accelerator Conference. For further information contact LINAC98@aps.anl.gov; http://www.aps.anl. gov/conferences/LINAC98.

\section{9}

4-13 August 1999: Glasgow, UK. XVIII IUCr Congress. For further information contact iucr99@chem.gla.ac.uk; http://www.chem. gla.ac.uk/iucr99.

\section{Notes and News}

\begin{abstract}
News items on synchrotron radiation science are published by the Journal of Synchrotron Radiation. Full or partial inclusion is subject to the approval of the Main Editors, to whom all correspondence should be sent.
\end{abstract}

\section{J. Synchrotron Rad. (1998). 5, 60}

\section{National Synchrotron Light Laboratory formally opened}

Brazilian president Fernando Henrique
Cardoso has officially opened
the National Synchrotron Laboratory.

The synchrotron light source designed and constructed at LNLS consists of a $1.37 \mathrm{GeV}$ electron storage ring and a $120 \mathrm{MeV}$ LINAC for low-energy injection. The storage ring has been commissioned and has already reached the design electron beam energy, current and emittance. The electron lifetime is now $7 \mathrm{~h}$ at $100 \mathrm{~mA}$, and is steadily being increased. Seven beamlines (TGM, SGM, SXS, XAFS, XRD, SAXS, $P C r$ ) have been constructed in parallel with the electron accelerators and are at present in operation. A total of 87 research projects used the facility during its first 4 months of operation.

A fuller account of the new light source will be given in the May 1998 issue of the journal. 